\title{
Interstitial Lung Disease Associated with Adult Niemann-Pick Disease Type B
}

\author{
Nader Chebib ${ }^{a}{\text { Françoise Thivolet-Bejuib }{ }^{\mathrm{b}} \text { Vincent Cottin }}^{\mathrm{a}, \mathrm{c}}$ \\ ${ }^{a}$ Department of Pneumology, National Reference Center for Rare Pulmonary Diseases and ${ }^{b}$ Department of \\ Pathology, Louis Pradel Hospital, Hospices Civils de Lyon, and ${ }^{\mathrm{C} C l a u d e ~ B e r n a r d ~ L y o n ~} 1$ University, University of \\ Lyon, INRA, UMR754, Lyon, France
}

A 66-year-old female presented with chronic dry cough and mild dyspnea. She had no medical history but reported Niemann-Pick disease (NPD) type B in her sister. Physical examination was normal except for hepatosplenomegaly. Pulmonary function tests showed a decrease in carbon monoxide diffusion capacity without obstructive or restrictive ventilatory pattern. Thoracic

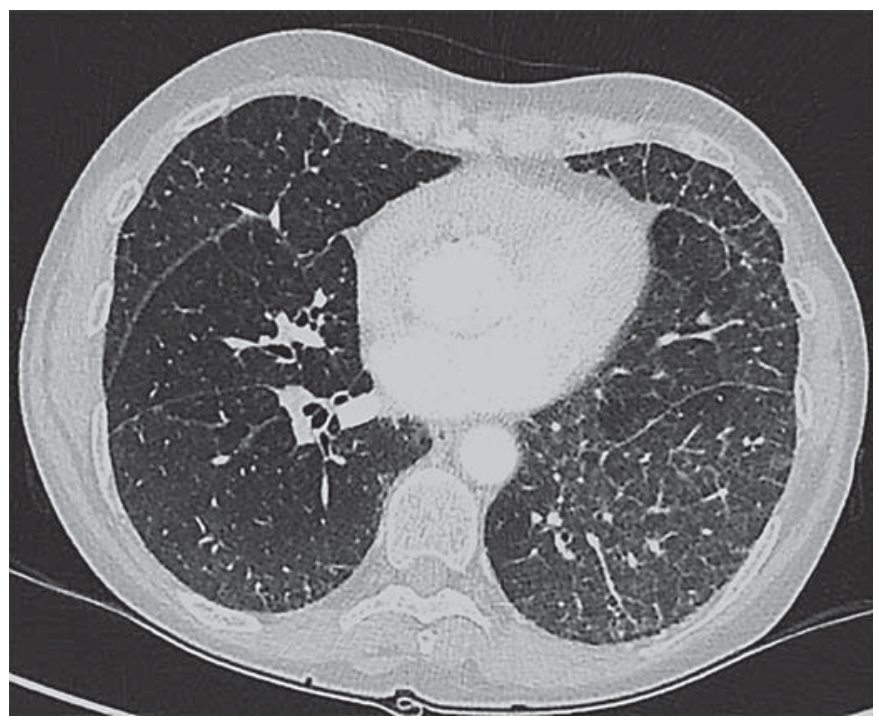

Fig. 1. Thoracic computed tomography showing ground-glass attenuation predominantly in the left lung, with interlobular septal thickening, compatible with interstitial lung disease in NiemannPick disease type B.

\section{KARGER}

๑) 2017 S. Karger AG, Basel

E-Mail karger@karger.com

www.karger.com/res computed tomography showed bilateral ground-glass opacities and interlobular septal thickening in the upper and lower lung zones (Fig. 1). Bronchoalveolar lavage showed predominance of "foamy" macrophages (93\%) (Fig. 2). Blood acid sphingomyelinase activity was decreased, and chitotriosidase activity was increased, as found in NPD type B. Genetic testing found a homozy-

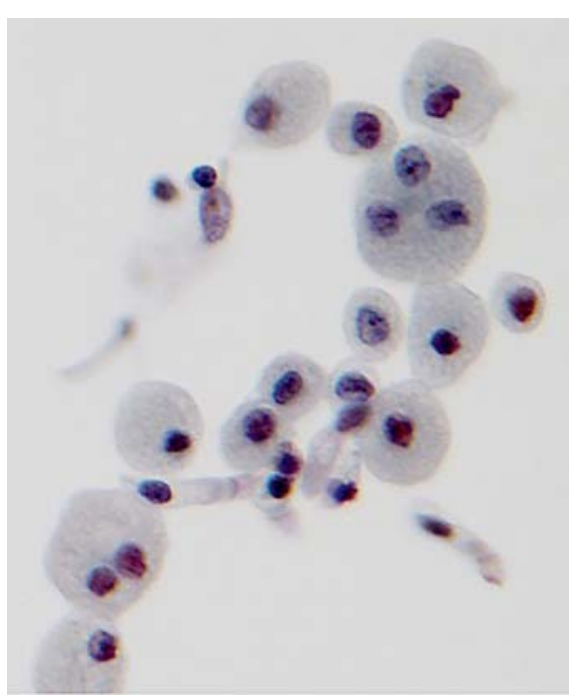

Fig. 2. Cytological analysis of bronchoalveolar lavage $(\times 40)$ after fixation with methanol and Papanicolaou stain, showing "foamy" macrophages (round cells with a large cytoplasm) containing multiple lipid-laden vacuoles. 
gous mutation (p.R610del) in the SMPD1 (sphingomyelin phosphodiesterase 1) gene, confirming NPD type B disease. Screening for autoantibodies was negative. No specific treatment was initiated. The patient's respiratory condition is stable after a 3-year follow-up.

NPD is a rare genetic lysosomal lipid storage disease, characterized by a defect in the sphingomyelinase enzyme activity. Pulmonary involvement is common in NPD type B, and mainly consists in progressive interstitial lung disease [1]. Radiological findings include groundglass opacities, thickened interlobular septa, intralobular reticulation, nodules, and cysts [2]. Respiratory outcome is generally favorable, although some cases may present with severe interstitial lung disease.

\section{Financial Disclosure and Conflicts of Interest}

The authors declare that there are no conflicts of interest concerning this paper.

\section{Author Contributions}

N.C., F.T.-B. and V.C. all contributed in the conception, design, analysis, and interpretation of the manuscript.

References

1 Nicholson AG, Florio R, Hansell DM, Bois RM, Wells AU, Hughes P, Ramadan HK, Mackinlay CI, Brambilla E, Ferretti GR, Erichsen A, Malone M, Lantuejoul S: Pulmonary involvement by Niemann-Pick disease. A report of six cases. Histopathology 2006; 48 : 596-603.

2 Mendelson DS, Wasserstein MP, Desnick RJ, Glass R, Simpson W, Skloot G, Vanier M, Bembi B, Giugliani R, Mengel E, Cox GF, McGovern MM: Type B Niemann-Pick disease: findings at chest radiography, thin-section $\mathrm{CT}$, and pulmonary function testing. Radiology 2006;238:339-345. 